\title{
Parameter correlations maintaining bursting activity
}

\author{
Anca Doloc-Mihu*, Ronald L Calabrese \\ From The Twenty Third Annual Computational Neuroscience Meeting: CNS*2014 \\ Québec City, Canada. 26-31 July 2014
}

In this study, we focused on the role of correlated conductances in the robust maintenance of functional bursting activity. Recent experimental and computational studies suggest that linearly correlated sets of parameters (intrinsic and synaptic properties of neurons) allow central pattern generating (CPG) neurons to produce and maintain their rhythmic activity regardless of changing internal and external conditions. However, the mechanisms that allow multiple parameters to interact, thereby producing and maintaining rhythmic network activity, are less clear.

For our study, we used our existing database (HCO$\mathrm{db})$ [1] of instances of a half center oscillator ( $\mathrm{HCO}$ ) model [2]. The HCO single-compartment conductancebased model [2] consists of two mutually inhibitory neurons and replicates the electrical activity of the oscillator interneurons of the leech heartbeat CPG under a variety of experimental conditions. From the database, we identified functional activity groups of isolated neuron and half-center oscillator (HCO) model instances and realistic subgroups of each such group that showed burst characteristics (principally period and spike frequency) similar to the animal. To find linear correlations among the conductance parameters maintaining functional leech bursting activity, we applied Principal Component Analysis (PCA) to each of these four groups. PCA identified a set of three maximal conductances (leak current, $\overline{\mathrm{g}}_{\text {Leak }}$; a persistent $\mathrm{K}$ current, $\overline{\mathrm{g}}_{\mathrm{K} 2}$; and a persistent $\mathrm{Na}^{+}$ current, $\bar{g}_{\mathrm{p}}$ ) that correlate linearly for the two groups of regular and realistic isolated neuron instances (Figure 1 A). Our 3D visualizations of $\mathrm{HCO}$ instances (Figure $1 \mathrm{~B}$ ) in the reduced space of $\overline{\mathrm{g}}_{\text {Leak }}, \overline{\mathrm{g}}_{\mathrm{K} 2}$, and $\overline{\mathrm{g}}_{\mathrm{P}}$ suggested that there might be a non-linear relationships between parameters for these instances.

A least square fit regression line (3D Orthogonal Distance Regression (ODR) line) to each group of isolated neurons (Figure $1 \mathrm{C}$ ) showed a tendency for the realistic instances to be at the high values on all axes and a tendency of the regular/not realistic instances to be at the low and middle values on all axes. From our analysis, it appears that none of the $\overline{\mathrm{g}}_{\text {Leak }}, \overline{\mathrm{g}}_{\mathrm{K} 2}$, or $\overline{\mathrm{g}}_{\mathrm{P}}$ parameters is sufficient by itself to produce regular and realistic isolated

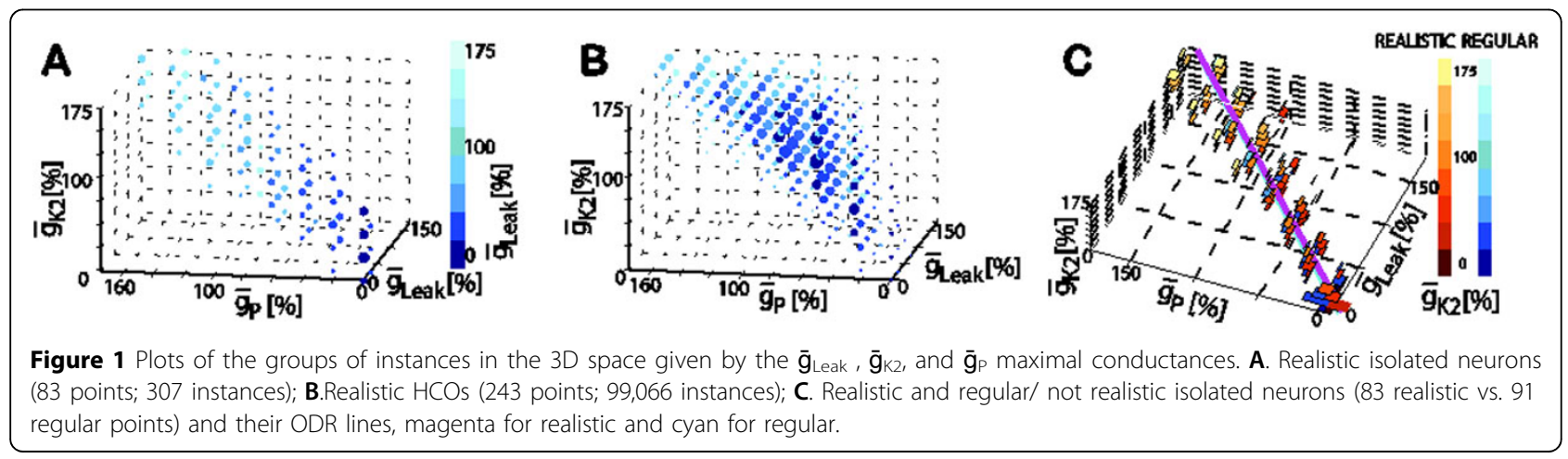

* Correspondence: adolocm@emory.edu
Department of Biology, Emory University, Atlanta, GA, 30322, USA 
neuron instances, but they must work together (in linear combination) in almost equal amounts towards producing the respective instances. Experimental studies have shown that period is a key attribute influenced by modulatory inputs and temperature variations in heart interneurons. Thus, we explored the sensitivity of period to changes in maximal conductances of $\overline{\mathrm{g}}_{\mathrm{Leak}}, \overline{\mathrm{g}}_{\mathrm{K} 2}$, and $\overline{\mathrm{g}}_{\mathrm{p}}$, and we found that for our realistic isolated neurons the effect of these parameters on period could not be assessed because when varied individually bursting activity was not maintained. Current studies are focused on determining which parameters can, when varied, smoothly control period, while maintaining bursting activity.

\section{Acknowledgements}

Work supported by the National Institute Health Grant NS085006 to R.L. Calabrese.

Published: 21 July 2014

\section{References}

1. Doloc-Mihu A, Calabrese RL: A database of computational models of a half-center oscillator for analyzing how neuronal parameters influence network activity. J Biol Physics 2011, 37:263-283.

2. Hill AAV, Lu J, Masino MA, Olsen OH, Calabrese RL: A model of a segmental oscillator in the leech heartbeat neuronal network. J. Comput Neurosci 2001, 10:281-302.

3. Cymbalyuk GS, Gaudry Q, Masino MA, Calabrese RL: Bursting in leech heart interneurons: Cell-autonomous and network-based mechanisms. J. Neurosci 2002, 2:10580-10592.

doi:10.1186/1471-2202-15-S1-09

Cite this article as: Doloc-Mihu and Calabrese: Parameter correlations maintaining bursting activity. BMC Neuroscience 2014 15(Suppl 1):O9.

\section{Submit your next manuscript to BioMed Central} and take full advantage of:

- Convenient online submission

- Thorough peer review

- No space constraints or color figure charges

- Immediate publication on acceptance

- Inclusion in PubMed, CAS, Scopus and Google Scholar

- Research which is freely available for redistribution

Submit your manuscript at www.biomedcentral.com/submit
C Biomed Central 